\title{
5-Hydroxytryptamine release into human jejunum by cholera toxin
}

\author{
C P Bearcroft, D Perrett, M J G Farthing
}

\begin{abstract}
Background-Cholera toxin produces intestinal secretion by activation of the adenylate cyclase complex. However animal studies have shown 5-hydroxytryptamine may be released after exposure to cholera toxin, and thereby contribute to the secretory state.

Aim-To determine whether cholera toxin releases 5-hydroxytryptamine in human jejunum.

Subjects-Seven male subjects were given a subclinical dose of cholera toxin in a paired, controlled, randomised, double blind study.

Methods-A closed $10 \mathrm{~cm}$ segment of upper jejunum was exposed to $15 \mu \mathrm{g}$ of cholera toxin for two hours prior to closed segment perfusion with plasma electrolyte solution containing a non-absorbable volume marker, $\left[{ }^{14} \mathrm{C}\right]$-polyethylene glycol. 5-Hydroxytryptamine in jejunal effluent and 5-hydroxyindoleacetic acid in urine (up to seven hours after cholera toxin) were measured by high performance liquid chromatography with fluorimetric detection.
\end{abstract}

Results-In contrast with controls, all subjects secreted fluid in response to cholera toxin, median $-2 \cdot 1 \mathrm{ml} / \mathrm{cm} / \mathrm{h}$ (interquartile range $-4 \cdot 1$ to $-0 \cdot 1$ ). During seven hours following cholera toxin, 5-hydroxytryptamine was secreted into the lumen (range 31 to $395 \mathrm{nmol} / \mathrm{l}$ ) but not in control experiments. After exposure to cholera toxin median urinary 5-hydroxyindoleacetic acid was $5 \cdot 7(4 \cdot 1$ to $6 \cdot 3)$, which was similar to controls $4 \cdot 9(4 \cdot 1$ to $6 \cdot 2)$.

Conclusion-Thus, cholera toxin induced a secretory state and promoted the release of 5-hydroxytryptamine into the intestinal lumen, but quantitative changes in urinary 5-hydroxyindoleacetic acid were not detectable. As an intestinal secretagogue, these findings suggest that 5-hydroxytryptamine may play a part in mediating cholera toxin induced secretion in humans.

(Gut 1996; 39: 528-531)

Keywords: cholera toxin, 5-hydroxytryptamine, 5-hydroxyindoleacetic acid.

St Bartholomew's School of Medicine and Dentistry, London

Correspondence to: Dr C P Bearcroft,

Digestive Diseases Research Centre, Medical College of St Bartholomew's Hospital, St Bartholomew's Hosp London EC1M 6BQ London EC1M 6BQ. Accepted for publication 28 May 1996

Vibrio cholerae releases cholera toxin (CT) into the small intestinal lumen, which is considered to be the major cause for secretory diarrhoea of human cholera. There are many studies to support the primary site of action of CT as being at the intestinal epithelium, where CT induced stimulation of adenyl cyclase leads directly to secretion of chloride ions and fluid. ${ }^{12}$ However in 1971 Bennett $^{3}$ suggested that CT may cause diarrhoea by stimulating prostaglandin synthesis and since the early 1980 s it has been appreciated that other mediators such as 5-hydroxytryptamine (5-HT) may be involved in the secretory mechanism. In $1983 \mathrm{Nilsson}^{4}$ showed that enterochromaffin cells of the cat small intestine discharge their contents of 5-HT after exposure to $\mathrm{CT}$ in vivo and that the decrease in intracellular 5-HT contents correlates closely with net fluid transport. Beubler et al ${ }^{5}$ reported CT induced 5-HT release in rat jejunal effluent, and further studies in our laboratory have confirmed CT induced mucosal depletion of 5-HT in rat small intestine. ${ }^{6}$ It has also been shown that 5-HT receptors are involved in the pathophysiology of cholera secretion as secretion is reduced after repeated exposure to 5-HT (tachyphylaxis) ${ }^{7}$ and by pre-treatment with the combination of $5-\mathrm{HT}_{2}$ and/or $5-\mathrm{HT}_{3}$ receptor antagonists. ${ }^{8}{ }^{9}$

Taken together these findings suggest that 5-HT is a biologically relevant mediator of CT induced secretion. However, there is no experimental evidence in humans to support the secretory role of 5-HT in cholera. A human cholera model was developed by Hunt et $a l^{10}$ in which microgram quantitites of highly purified CT is introduced in a segment of human jejunum isolated between two occluding balloons, resulting in a secretory state without causing clinical diarrhoea. Using this model we have examined whether CT causes release of 5-HT into jejunal effluent in humans.

\section{Methods}

\section{Subjects}

Seven male healthy volunteers (age range 19 to 23 years) were enrolled in the study. The study protocol was approved by the City and Hackney Health District Research Ethics Committee. All subjects gave signed, informed consent before starting the study. Total radiation dosage was less than $2 \mathrm{mSv}$ per subject.

\section{Small intestinal perfusion}

Highly purified CT, prepared originally for human vaccine studies, was obtained from the Swiss Serum and Vaccine Institute (Berne, Switzerland). It was stored in $15 \mu \mathrm{g}$ aliquots, dissolved in phosphate buffered saline (PBS) in 
gelatine coated vials at $-70^{\circ} \mathrm{C}$. After an overnight fast, healthy human volunteers, were intubated by mouth and the perfusion tubes positioned in the proximal jejunum under fluoroscopic control. Gastric contents were aspirated via a proximal collection port on the perfusion tube and a nasogastric tube, which was used concurrently. A reproducible, stable secretory state was produced (Fig 1) by exposing a $10 \mathrm{~cm}$ segment of jejunum to $15 \mu \mathrm{g}$ cholera toxin in $10 \mathrm{ml}$ PBS for two hours, isolated between two occluding balloons, as described previously. ${ }^{10}$ The proximal balloon was confirmed to be effectively occluding the intestine in each study by introducing phenol red into the distal duodenum through a port in the perfusion tube assembly and confirming that it did not appear in the effluent from the test segment. There was $88 \cdot 8(87 \cdot 2-96 \cdot 3) \%$ recovery of radioactive marker PEG confirming occlusion by the lower balloon. In paired control studies in the same subjects, at least one week apart, the same volume of PBS was given alone.

After the establishment of a CT induced secretory state, the isolated closed segment was perfused slowly with plasma electrolyte solution (PES) at $1.5 \mathrm{ml} / \mathrm{min}$ for five hours.

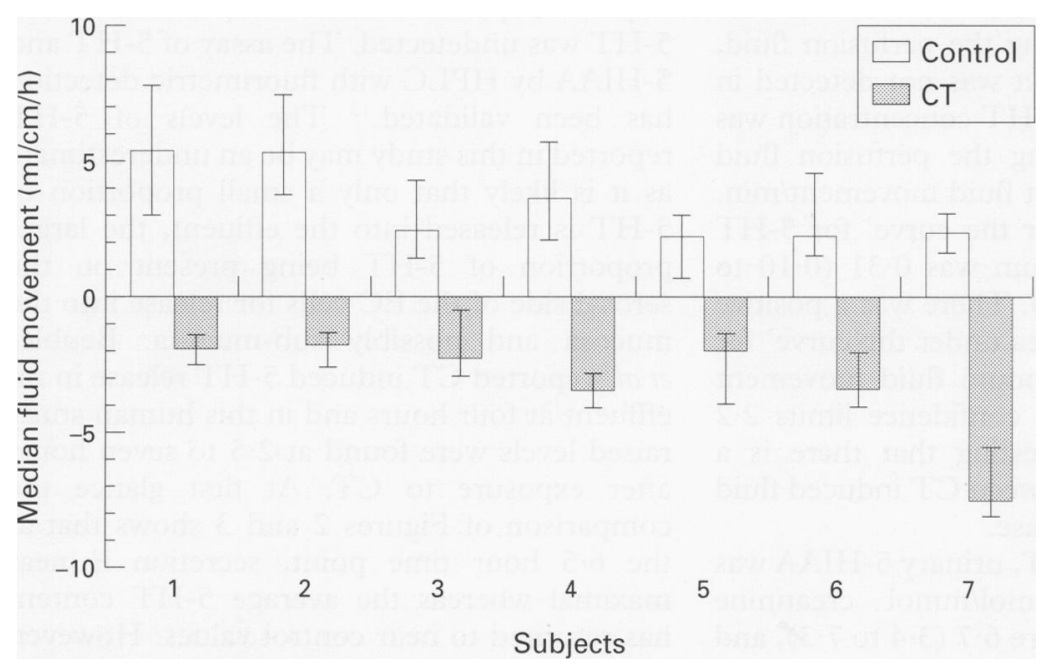

Figure 1: Median fluid movement (IQR) in human jejunum after two hour exposure to $C T$ in seven subjects and controls (+ denotes absorption, - denotes secretion) $(n=10)$.

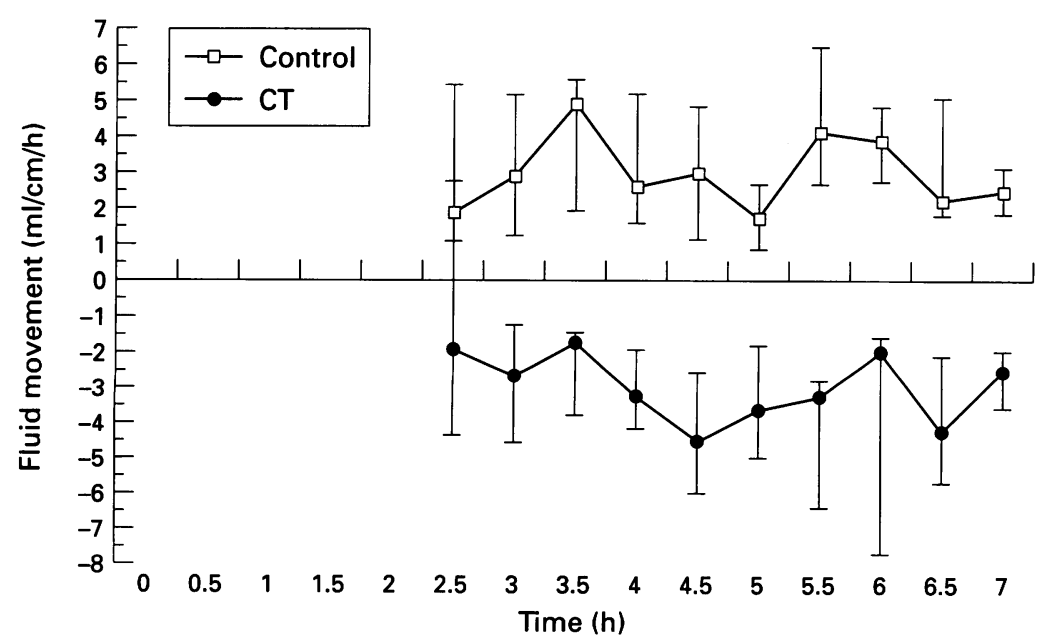

Figure 2: Profiles of median net fluid movement (IQR) in human jejunum after two hour exposure to CT in seven subjects and controls (+ denotes absorption, - denotes secretion).
PES (Na 140, K 4, $\left.\mathrm{HCO}_{3} 40, \mathrm{Cl} 104 \mathrm{mmol} / \mathrm{l}\right)$ also contained polyethylene glycol (PEG) 4000 $2.5 \mathrm{~g} / 1$ and ${ }^{14}$ [C]-PEG (Amersham International, Herts, UK) $2 \mu \mathrm{Ci} / 1$ as a nonabsorbable volume marker. During the following five hour period jejunal effluent was sampled at 30 minute intervals. The subjects were asked to completely empty their bladders before, during, and after exposure to CT and the urine was collected.

Effluent and urine were collected into plain bottles and immediately centrifuged at $1500 \mathrm{~g}$ at $4^{\circ} \mathrm{C}$ for 10 minutes and cell free supernatant was frozen at $-20^{\circ} \mathrm{C}$.

Analytical procedures and calculation of results Secretion or absorption as represented by change in the concentration of the radioactive marker, ${ }^{14}[\mathrm{C}]-\mathrm{PEG}$, was measured using an LKB Wallace 1219 liquid scintillation counter programmed to correct for quenching of scintilllation activity due to bile contamination of the solutions. ${ }^{11}$ A sample $(0.5 \mathrm{ml})$ was diluted in $4.5 \mathrm{ml}$ of scintillation fluid (Optiphase Safe, Pharmacia Wallace (UK), Milton Keynes). Samples were counted in triplicate and the results calculated by the standard formulae. ${ }^{12}$ Net fluid transfer is expressed in $\mathrm{ml} / \mathrm{cm} / \mathrm{h}$. Net absorption is expressed by a positive value and net secretion by a negative value. Jejunal effluent was analysed for the presence of 5-HT and urine for the 5-HT metabolic product, 5-hydroxyindoleacetic acid (5-HIAA) by HPLC with fluorimetric detection. ${ }^{13}$ Urinary creatinine was determined by cation exchange HPLC with ultraviolet detection.

\section{Statistics}

The results are expressed as medians (interquartile ranges (IQR)) and fluid movement in CT and control experiments was compared by Wilcoxon rank sum test. The relation between 5-HT secreted per $\mathrm{cm}$ of jejunum, expressed as 'area under the curve' $(\mathrm{h} / \mathrm{nmol} / \mathrm{cm})$ and fluid movement $(\mathrm{ml} / \mathrm{cm} / \mathrm{h})$ was compared by linear regression.

\section{Results}

Net fluid movement and 5-HT release

All subjects secreted fluid in response to cholera toxin (median value $-2 \cdot 1(-4 \cdot 2$ to $-0 \cdot 1) \mathrm{ml} / \mathrm{cm}$ / $h$ derived from individual half hourly measurements obtained over five hours). In control subjects there was net absorption ( $2 \cdot 8$ $(1.8$ to 5.3$) \mathrm{ml} / \mathrm{cm} / \mathrm{h}$ ) (Fig 1). The profiles of fluid movement during the course of the control and CT experiments are shown in Figure 2. Fluid movement was not determined from 0 to two hours during CT exposure in the test segment. From 2.5 to three hours after CT, there was net absorption in subjects 2,3 , and 5 , but between three and seven hours CT induced net secretion in all subjects, which remained constant, stable, and significantly different from controls $(p=0 \cdot 0001)$ (Wilcoxon 


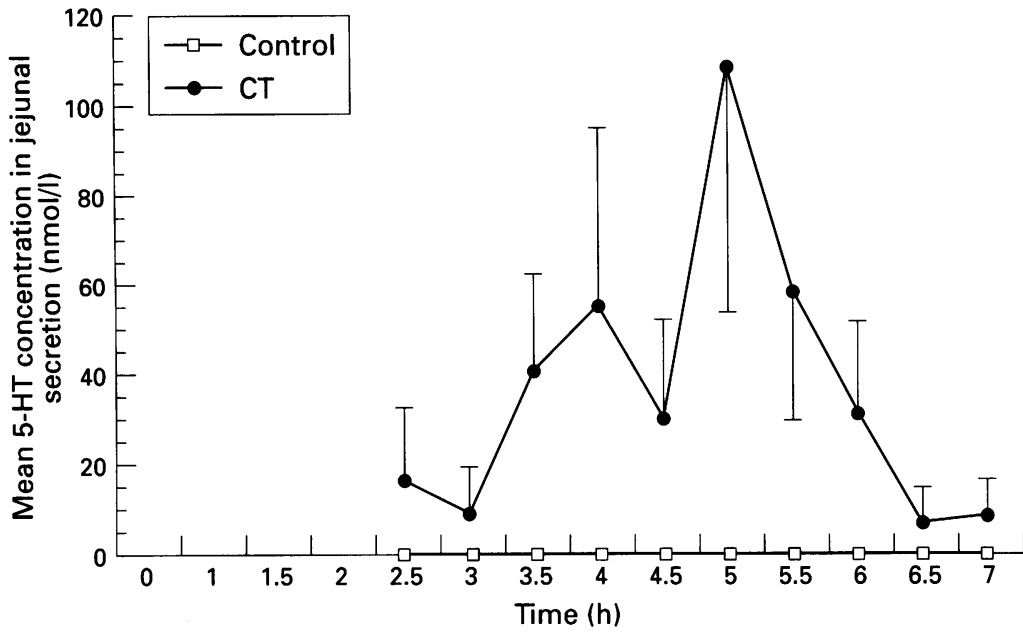

Figure 3: Mean (SEM) 5-HT concentration in jejunal secretion in seven subjects during seven hours after exposure to $C T$. after exposure $5 \cdot 7(4 \cdot 1$ to $6 \cdot 3)$. There was no significant difference between these and values in control subjects who did not receive cholera toxin, $5.2(4.0$ to 6.3$)$ before, 5.7 (3.9 to 6.9$)$ during, and $4.9(4 \cdot 1$ to $6 \cdot 2)$ after placebo.

\section{Discussion}

We have shown in this study that CT induces intestinal fluid secretion in human jejunum, which is accompanied by the release of $5-\mathrm{HT}$ into the intestinal lumen. In a histological study Nilsson et al showed CT induced depletion of enterochromaffin cell 5-HT in the cat. ${ }^{4}$ In the rat, Beubler et al showed CT induced 5-HT release into jejunal effluent ${ }^{5}$ and Turvill et al showed CT induced 5-HT depletion from jejunal mucosa. ${ }^{6} 5-\mathrm{HT}$ is known to be an intestinal secretagogue and thus these findings in humans support the previous data in experimental animals, that 5-HT may mediate, at least in part, the secretory activity of CT and the production of high volume watery diarrhoea in cholera.

The reliability of the results in this study depend upon the precision of the perfusion technique and measurement of 5-HT. The 5-HT release was shown not be be a function of jejunal intubation, as exactly the same technique was applied in control experiments when 5-HT was undetected. The assay of 5-HT and 5-HIAA by HPLC with fluorimetric detection has been validated. ${ }^{13}$ The levels of $5-\mathrm{HT}$ reported in this study may be an underestimate as it is likely that only a small proportion of 5-HT is released into the effluent, the larger proportion of $5-\mathrm{HT}$ being present on the serosal side of the EC cells for release into the mucosa and possibly sub-mucosa. Beubler et $a l^{5}$ reported CT induced 5-HT release in rat effluent at four hours and in this human study raised levels were found at 2.5 to seven hours after exposure to CT. At first glance the comparison of Figures 2 and 3 shows that at the 6.5 hour time point, secretion is near maximal whereas the average $5-\mathrm{HT}$ content has returned to near control values. However, on an individual subject basis, correlation between the total amount of 5-HT released expressed as 'area under the curve' and maximum fluid movement at the time of 5-HT release may indicate that $5-\mathrm{HT}$ is released in proportion to fluid movement. Alternative explanations are that the post-release washout of $5-\mathrm{HT}$ is in proportion to the magnitude of water secretion via paracellular pathways or that 5-HT is important in the initiation of CT induced secretion. We were unable to detect the CT induced changes in urinary 5-HIAA. It is probable that any increment in urinary 5-HIAA was too small to significantly influence the much larger variations of 5-HIAA excretion that occurs naturally.

Although release of 5-HT has been shown to be part of CT induced secretion in animals, this is the first study to show a similar effect in humans. This study provides further evidence that 5-HT may be an important mediator of the secretory process induced by CT and suggests that $5-\mathrm{HT}$ receptor antagonism may
Figure 4: Linear regression of 5-HT secreted per $\mathrm{cm}$ of jejunum 'area under the curve', and maximum fluid movement at time of 5-HT release ( $\mathrm{r}=0 \cdot 78, p=0.008,95 \%$ confidence limits $2 \cdot 2$ and $6 \cdot 1$ ). 
have a therapeutic part to play in the pharmacological control of secretory diarrhoea.

CPB was supported by an Alimentary Pharmacology and Therapeutics Trust/British Digestive Foundation Fellowship.

1 Carpenter C. The pathophysiology of secretory diarrhoeas. Med Clin 1982; 66: 597-610.

2 Powell D, Field $M$. Pharmacological approaches to treatment of secretory diarrhea. In: Field M, Fordtran J, ment of secretory diarrhea. In: Field M, Fordtran J, Physiological Society 1980: 187-207.

3 Bennett A. Cholera and prostaglandins. Nature 1971; 231 536.

4 Nilsson O, Cassuto J, Larsson P-A, Jodal M, Lindberg P, Ahlman $\mathrm{H}$, et al. 5-Hydroxytryptamine and cholera secretion: a histochemical and physiological study in cats. Gut 1983; 24: 542-8.

5 Beubler E, Kollar G, Saria A, Bukhave K, Rask-Madsen J. Involvement of 5-hydroxytryptamine, prostaglandin $\mathrm{E}_{\mathrm{i}}$ and cyclic adenosine monophosphate in cholera toxininduced fluid secretion in the small intestine of the rat in vivo. Gastroenterology 1989; 96: 368-76.

6 Turvill J, Mourad F, Perrett D, Farthing M. Tissue 5-hydroxytryptamine (5-HT) content in rat small intestine in absorptive and secretory states. Gut 1994; 35 (suppl 5): S54.

7 Cassuto J, Jodal M, Tuttle R, Lundgren O. 5-hydroxytryptamine and cholera secretion. Physiological and pharmacological studies in cats and rats. Scand $\mathcal{F}$ Gastroenterol 1982; 17: 695-703.

8 Beubler E, Horina G. 5- $\mathrm{HT}_{2}$ and 5- $\mathrm{HT}_{3}$ receptor subtypes mediate cholera toxin-induced intestinal fluid secretion in the rat. Gastroenterology 1990; 99: 83-9.

9 Mourad F, O'Donnell L, Dias J, Ogutu E, Farthing M. Role of 5-hydroxytryptamine type 3 receptors in rat intestinal fluid and electrolyte secretion induced by cholera toxin and Escherichia coli enterotoxins. Gut 1995; 37: 340-5.

10 Hunt J, Thillainayagam A, Carnaby S, Fairclough P Clark M, Farthing M. A new model of human secretory diarrhoea using cholera toxin. Aliment Pharmacol Ther 1992; 6: 619-27.

11 Hunt J, Elliot E, Farthing M. Efficacy of a standard United Kingdom oral rehydration solution (ORS) and a hypotonic ORS assessed by human intestinal perfusion. Aliment Pharmacol Ther 1989; 3: 565-71.

12 Hicks $T$, Turnberg $\mathrm{L}$. The influence of secretin on ion transport in the human jejunum. Gut 1973; 14: 485-90.

13 Bearcroft C, Farthing M, Perrett D. Determination of 5-hydroxytryptamine, 5-hydroxyindoleacetic acid and tryptophan in plasma and urine by HPLC with fluorimetric detection. Biomed Chromatogr 1995; 9: 23-7. 